\title{
\begin{tabular}{llllllllllllllllll}
$T$ & $\ddot{U}$ & $\mathrm{R}$ & $\mathrm{K}$ & & $\mathrm{T}$ & $\mathrm{A}$ & $\mathrm{R}$ & $\mathrm{I}$ & $\mathrm{H}$ & & $\mathrm{K}$ & $\mathrm{U}$ & $\mathrm{R}$ & $\mathrm{U}$ & $\mathrm{M}$ & $\mathrm{U}$ \\
\hline
\end{tabular} \\ BELLETEN
}

\section{URARTU BAHÇELERI}

\section{VELI SEVIN*}

Eskiçağ'da gerek Doğu ve gerekse Batu dünyasında bağ bahçe sahibi olmak bir gurur kaynağı ve bir ayrıcalık göstergesiydi. Bu yüzden krallar, beyler, soylular ve tapınaklar büyük gayretler göstererek çeşitli bağ, bahçe ve koruluklar kurmaya özen gösterirler, ozanlar onlardan övgüyle söz ederlerdi. Tevrat'ta (Vaiz 2:4-6; Wiseman 1983: 143) Süleyman'ın Kudüs'teki üzüm bağları, meyve bahçeleri ve parkları anlatulıyor, Homeros'ta ise Phaiak kralı Alkinoos'un bahçesi (Odysseia VII 111 vd.) ve bağı (VII 137 vd.) uzun uzun betimleniyordu.

Doğu'da Babil'in asma bahçeleri Dünya'nın 7 Harikası arasına girecek denli ün salmıştı' ${ }^{1}$ Assur kralları en azından I. Adad-Nirari (İÖ. 1307-1275) döneminden beri meyve bahçeleri kurmak için gayret göstermeye başlamışlardı (Grayson $1972: 478$ ). Bu bahçelerde türlü türlü bitkiler ve ağaçlara yer verilmiş, hatta bunlardan önemli bir bölümü Assur dışındaki yabancı diyarlardan sağlanmışu (Grayson 1976: 47.[vı. 17]). Nitekim Assur eyalet sistemi içinde yöneticiler başkent bahçeleri için meyve fidanı toplama görevi ile de yükümlüydüler (Parpola 1987: No. 222,226)².

* Prof. Dr. Veli Sevin, Canakkale Onsekiz Mart Üniversitesi, Güzel Sanatlar Fakültesi Dekan, ÇANAKKALE

Bu çalışma İstanbul Üniversitesi Araşturma Fonu'nca desteklenmektedir: Proje No. $613 / 210494$.

'Babil'in asma bahçeleri hakkunda tüm antik kaynaklar için blz. Stevenson 1992. Bu bahçenin aslında Ninive'deki Sennaherib sarayını önündeki bahçeler olabileceği hakkında bliz. Dalley 1994.

2 Sennaherib'in Ninive'deki sarayım duvarlarındaki kabartmalarda krali bahçeler için toplanan meyve fidelerinin çömlekler içinde tașııșı sahnesi resmedilmiștir: Parpola 1987: res. 37. 
Assur'da bahçeler çeşitli amaçlara hizmet etmekteydi. Bunlardan biri, daha çok başkentlerin dışında, büyük av ve botanik parklanı (kirû, ambassu ) şeklindeydi; bir başka tür ise, saraya bitişik olan daha küçük keyif-zevk bahçelerini ve meyvelikleri (kirimāhu) kapsıyordu. İçinde küçük bir köşk ya da yazlık (bitānu) bulunan bu ikinci tür ilk kez II. Sargon (IÖ.721-705) döneminden itibaren ortaya çıkmaya başlamıştı ve daima bir yükselti üzerine kurulmuştu (Oppenheim 1965; Wiseman 1983) (Res. 1-2). Hatta bu yüzden, çok daha sonraları (İÖ. I. yüzyılın ortaları) Diodoros Sicilus (II, 10) Ninive'deki bu bahçelerin bir tiyatro gibi geriye doğru yükseldiğini anlatır. İÖ. VIII. yüzyılın sonlarından başlayarak inşa edilmiş bu zevkü sefa bahçeleri pek çok yönden Osmanlı dönemindekilerle karşılaştırılabilir³. Örneğin Evliya Çelebi (Seyahatnâme 1, 81 vd.) Topkapı Sarayı'nın çepeçevre bahçelerle kuşatıldığını, içlerinde servi, çınar, ardıç, çam, şimşir gibi türlerden 20.000 ağaç bulunduğunu, tam ortada ise gönül açıcı, havası hoş bir tepe üzerinde özel odalar bulunduğunu bildirir.

Bağ bahçe kurmaya önem vermiş uluslar arasında Urartular'ın adları da ön planda sayılabilir. En azından İspuini (İÖ. 830-820) döneminden başlayarak kralların daha çok Van Gölü havzasında üzüm bağları ( $\mathrm{GIS} \hat{S}_{\text {ul-di/e, }}$

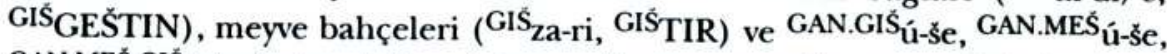
GAN.MEŠ.GIŠ ú-še (sebze bahçesi, bostan ?) yaratmaya önem verdikleri anlaşılmaktadır (Burney 1972; Zimansky 1985: res. 11) 4 . Gerçekten de İspuini'den II. Rusa'ya (İÖ. 675-650) değin tahta çıkan tüm krallar günümüze, bu türde bahçeler kurduklarına ilişkin yazıtlar bırakmışlardır (UKN No. 27, 65, 99, 111, 137, 167, 172, 275, 268,281; Balkan 1960: 150 vd.; Belli, Dinçol 1980: 178; Dinçol, Belli 1982: 178; Dinçol, Kavaklı 1978: No. 1-2; Çilingiroğlu, Salvini 1995: 118 vd. ; Zimansky 1985: 69 vd.). Hatta bağ ve bahçe kurma, çoğu kez kentlerin kuruluşu ile birlikte anılması gerekli, kalıplaşmış bir etkinlik halini almıştur. Bunun yanında Assur kralı II. Sargon ise ünlü 8. Seferi sırasında (İÖ. 714) Urmiye Gölü yöresindeki Ulhu kentinin I. Rusa (İÖ. 730713) tarafindan yaptrılmış sulama kanalları, meyve bahçeleri ve üzüm bağla-

${ }^{3}$ Osmanlı dōnemi bahçeleri için bkz. M. Erdoğan, "Osmanlı Devrinde İstanbul Bahçeleri", Vakıflar Dergisi IV, 1958: 149 vdd.; S. H. Eldem, Türk Bahçeleri, Ankara 1976; G. Arslanoğlu Eıyapan, Eski Türk Bahçeleri ve Özellikle Eski İstanbul Bahçeleri, Ankara 1972.

+ Özellikle İspuini ve Minua'nın Karahan'da bulunan yazıtlannda üzüm bağı ve meyve bahçesiyle birlikte bir de "bur-ga-na-ni" kurulduğu bildirilir; ancak olasılıkla "otlak" ve belki de "yoncalık" ya da "tarla" olarak çeırilebilecek bu sỏzcüğün anlamı taruşmalıdır: Dinçol, Kavakłı 1978: No. 1 ve 2; krş. Balkan 1960: 144 vd. 
rından uzun uzun söz eder (LAR II, 160; Zaccagnini 1981: 265 vdd.). V. yüzyıl tarihçisi Khroneli Movses (3. 1) ise Van Gölü kıyısındaki Tuspa (?) kentinin doğu, kuzey ve güney taraflarında pek çok meyve bahçesi, koruluk, üzüm bağı ve teraslı bahçeler bulunduğunu anlaur.

Urartu kralları tarafından kurdurtulan krali bahçeler çoğu kez onların adıyla anılıyordu: Örneğin ${ }^{m}$ Me-i-nu-ú-a-i GIŚ du-ri-ni-i GIŚ ú-du-li-e-i (Sarduri Bağı) gibi. Bahçeler kimi zaman tanrılar adına da düzenlenebilmekteydi. Nitekim ünlü Meherkapı yazıtında İspuini ve oğlu Minua'nın tanrı Haldi için bir üzüm bağı yaptırttıklarından söz edilmektedir (UKN No. 27). Bu bağ olasılıkla Meherkapı kaya anıunın yakınlarında ve Zim Zim Dağı'nın güney etekleri üzerinde olmalıydı (Belli 1998: 31).

Urartu'da kralların yanında saraylı kadınlar ve soyluların da bu türde bahçelere sahip olma hakları vardı. Sözgelimi Minua'nın (İÖ. 810-785/80), sonraları Şamram Kanalı denen ünlü kanalına $\left({ }^{m} \mathrm{Me}\right.$-i-nu-a-i pi-li = Minua Kanalı) bitişik olarak kurulmuş üzüm bağı kızı ( ${ }^{S A L}$ si-la) (Zimansky 1985: 69 ve not 136) ya da daha büyük bir olasılıkla karısı (Salvini 1998: 97 vdd.) Tariria'nın adını taşıyor ve Taririahinili olarak adlandırılıyordu (UKN no. 111). Van'da bulunmuş bir stel üzerindeki yazıtta ise Rusaoğlu Argisti'nin (İÖ. 713-?) okunu, Gilurani'nin meyve bahçesinden (GIŚ TIR) Batuoğlu İspili'nin bahçesine (GIŠ NU.SAR) ${ }^{5}$ değin fırlatuğı anlatılmıştır (UKN no. 277). Bastam'dan bir kil tablette de kale yöneticisi Lubsuiani ile rakibi Adiabdi arasında çekişme konusu olan bir fidanlıktan (GIŚú-u-du-ute-e ) söz edilmektedir (Salvini 1979: 118, 121). Bütün bunlardan Urartu'da bağ-bahçe sahibi olma ayrıcalığının yalnızca krallara özgü olmadığı sonucuna varılabilir.

Bu yazılı bilgilere karşın Urartu bahçelerinin biçim ve konumları hakkında fazla bilgi yoktur. Assur kabartmalarında II. Sargon döneminden başlayarak kirimahu denen bahçelerde tam anlamıla altlıklı ve başlıklı sütuna benzeyen taşıyıcı ögeleriyle pavyonlara yer verildiği bilinmektedir. Bunlar bazen bir su kıyısında (Res. 1), bazen de bir koruluğun üzerinde (Res. 2) yer alırlar; içlerinde sunaklar ve kutsal alanlar bulunur. Urartu bahçelerinde de bu türde köşkler-pavyonlar ve dinsel ögeler var mıydı ? Varsa nasıldı ? Bu soruların yanıtlarını bulmak pek kolay değildir.

\footnotetext{
${ }^{5}$ HchI 151 not 9'da Kõnig bu sôzcüğūn anlamının tam açık olmadığım bildirir.
} 
Urartu kabartmaları üzerinde ne yazık ki parklar-bahçeler resmedilmemiştir; ancak bağ ve bahçelerin daima iyi sulanan bölgelerde konumlandırıldığı da kuşkusuzdur. Sözgelimi II. Sargon'un Ulhu ile ilgili anlatımlarında, içinden Fırat gibi bol su akan büyük bir kanaldan açılan küçük kollarla beslenen bahçelerden söz edilir (Laessøe 1951; Zaccagnini 1981: 265). II. Assurnasirpal Kalhu meyveliklerini Yukarı Zap ırmağından açtığı PattiHegalli adlı kanalın çevresinde kurdurduğunu bildirir (Grayson 1976: 591.[III 132]; 619.[v 1]; 678.[37]). Aym şekilde, Urartu krallarından I. Argişti, Armavir yakınlarında bulunan bir yazıtında (UKN no. 137) Aras ırmağından açurttı̆ı dört kanal üzerinde üzüm bağı ve meyvelikler yaptırtuğını; II. Rusa da (UKN no. 268) Erek Dağı üzerindeki Keşiş Gölü yakınından ele geçirilen bir yazıtta, Rusa (Keşiş) Gölü'nden açtırtuğı bir kanalla Rusahinili (Toprakkale) yöresinde üzüm bağı, meyve ve sebze bahçeleri açurtuğım anlatur.

Su kanalları ile bahçeler arasındaki yakın ilişki Minua'nın ünlü kanalı ile Taririahinili denen bağda görülebilir. Kanalın destek duvarları üzerine kazılmış in-situ durumdaki yazıtu nedeniyle Van kent merkezinin 14 km. kadar güneyinde, Edremit ilçesindeki Kadembastı (eski Katepans) yöresinde olduğu anlaşılan bu bağ Minua Kanalı'nın hemen önündeki yapay teraslar üzerine kurulmuş olmalıydı (Lehmann-Haupt 1926: 108; Öğün 1970: 34; Salvini 1992; Belli 1995: 54 vd.; 1997: 15 vd.). Böylelikle Urartu bağ ve bahçelerinin krallarca açurılan su kanalları çevresinde kurulduğu ve bu kanallardan çekilen arklarla sulandığı anlaşılmaktadır (Belli 1997 : 637 vd.). Bu yüzden Gürpınar Ovası'ndan Van Ovası'na doğru uzanan 51 km.lik Minua Kanalı boyunca Taririahinili gibi pek çok bağ ve bahçenin varolduğu söylenebilir.

Urartu kralları kısa ve tümüyle yağışsız geçen yaz aylarında bağ ve bahçelerini sulayabilmek amacıyla, öteki Yakın Doğı hükümdarları gibi yapay göller ve göletler de inşa etmişlerdi. Nitekim II. Argişti (UKN no. 276) ve II. Rusa (UKN no. 268) bu türde etkinliklerini kazdırtukları yazıtlarında bizzat anlaturlar. Van Gölü havzasında, kalıntıları günümüze değin gelebilmiş pek çok Urartu barajının varlığı bilinir (Öğün 1970; Belli 1994; 1995b; 1997ª $\left.1997^{\circ}\right)$. Özellikle Van Ovası'nın Minua Kanalı'nca sulanamayan, Erek Dağı'nın batı etekleri üzerinde, Urartular döneminde çok sayıda gölet kurulduğu ve buna bağlı olarak ovanın doğu kesiminde pek çok bahçenin varlığı anlaşılmaktadır (Garbrecht 1980: 310 vdd., res. 3; Belli 1997b: 164 vdd., 


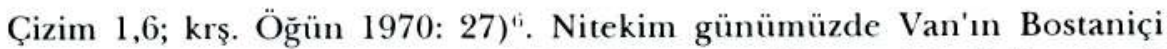
(Sıhke), Karpuzalanı (Zırvandanis) ve Kavuncu (Çoravanis) gibi bereketli köyleri hep bu kesimde yer almaktadır. Bu verilerden hareketle Urartu bahçelerinin kentlerin dışında ve özellikle de su kanalları ile baraj gölleri yakınlarında yer aldığı söylenebilir.

Urartu bahçelerinin türleri ve büyüklükleri konusunda hemen hiç bir bilgi yoktur. Assur'da olduğu gibi büyük av ve botanik parklarına sahip miydiler? Yoksa Urartu bahçeleri yalnızca pratik amaca yönelik daha küçük meyveliklerden mi ibaretti ? Henüz bu soruların doyurucu yanıtları verilemez; ancak Rusaoğlu Argişti'nin okunu Gilurani'nin ormanından Batuoğlu İspili'nin bahçesine değin (950 1-Ú) firlatmış olması -bu uzunluk ölçüsünün günümüzdeki karşılı̆̆ açık değilse de- hiç olmazsa özel bahçelerin birkaçyüz metreden daha geniş olamayacağına işaret eder gibidir. Urartu ve Assur yazıtları Urartu'da büyük botanik ve av parklarından çok, daha küçük meyveliklerin bulunduğu yolunda kimi kantlar sağlar. Sözgelimi II. Sargon'un Ulhu kentine ilişkin anlatımları ile Kadembasu (Taririahinili) ve Meherkapı yöresi bağlarının konumları, fazla güçlü olmasa da, böyle küçük bahçelerin varlığına birer kanıt olarák ele alınabilir ${ }^{7}$.

Konumları ve hatta büyüklükleri hakkında az da olsa bilgi sahibi olabildiğimiz, pratik yarara yönelik Urartu bahçelerinin içindeki olası yapılar hakkında hiçbir şey bilinmez. Bununla birlikte, Çavuştepe (eski Sardurihinili) Urartu kalesinin güneyinde, 1980'li yılların ikinci yarısında su kanalı yenileme çalışmaları sırasında saptanan taştan bir direk altı̆̆ı kanımca bu konuda kimi öneriler getirmemize olanak tanıyacak niteliktedir (Res. 3). Gri renkli yumuşak kum taşından yapılmış bulunan bu altlık $1.20 \mathrm{~m}$. çapında ve yaklaşık $0.30 \mathrm{~m}$. kadar yüksekliktedir (Res. 4, 5-a). Bugün, ne yazık ki, üst kısmı köylülerce kısmen kırılmış ve günümüze $0.24 \mathrm{~m}$. yüksekliğinde bir bölüm kalmıştur. Gayet özenli bir işçiliğin ürünü olan altlığın dipten üste doğru $0.11 \mathrm{~m}$.lik bir bölümü daha kaba bir işçilikte bırakılmıştur. Böylelikle taşın sabit olarak bir zemine oturtulduğu ve alttaki kaba bölümünün de görünmeyecek şekilde tasarlandığı anlaşılmaktadır.

'A.H. Layard (Niniveh and Babylon, London 1853: 392) XIX. yüzyılın ortalarında Van'a yaptığı ziyaret sırasında kentin, Yedi Kilise (Erek) dağlarındaki kaynaklardan yapay arklarla getirilen sularla beslenen bağlar ve meyveliklerle çevrili olduğunu anlatur. Bu yüzden Erek dağı gōlet sistemleri ele alımırken daima bu noktanın gōz ōnünde bulundurulması yararlı olacakur.

${ }^{7}$ Diodorus Sicilus (II, 10) ve Strabon (XVI 1.5) Babil'deki bir asma bahçesinin her yönden 400 plethron ( $300 \mathrm{~m}$. kadar) genişlikte olduğunu bildirirler. 
İlk bakışta söz konusu direk altlığının Așağı Kale'den yuvarlanmış olabileceği akla gelir. Nitekim eteklerde, özellikle surlardan yuvarlanan yüzlerce taş blok hala görülebilmektedir; ancak ötekilerden farklı olarak bu, kolaylıkla kırılabilen yumuşak kum taşındandır. Bu nedenle de hiç zedelenmeden o denli yüksekten bulunduğu eteğe değin yuvarlanması oldukça kuşkuludur. Ayrıca, Aşağı Kale'nin çok büyük bir bölümü kazılmış olup bu boyutta bir altlığın varlığına ilişkin en küçük bir kanıt elde edilebilmiş değildir. İrmuşini Tapınağı'nın doğusundaki büyük şarap mahzeninde kullanılan ve doğrudan doğruya kaya zemine oturtulmuş taştan silindirik kaideler Urartu'nun çok bilinen türlerine girerler (Erzen 1978: lev. IX/a). Şimdiye değin Urartu mimarlığında bu denli geniş çaplı ve bu denli dayanıksız malzemeden direk altlığı kullanıldığına ilişkin kanıt yoktur. Altuntepe'nin andezit direk altlıkları $0.70 \mathrm{~m}$. (Özgüç 1966: 3, lev. X/1-2, XI/1-2, XII/1) Kayalıdere'dekiler ise $0.77 \mathrm{~m}$. çapındadır (Burney 1966: 67, lev. XVII/c, XXI/c).

Urartu'da ağır taşıyıcı altlıklar genelde bazalt-andezit türündedir ve bunlar yumuşak bir zemine cturtulmak zorundaysalar, alttaki görünmeyen kısımlar çok kaba ve üstteki bölümden daha şişkin olacak şekilde hazırlanmışlardır (Res. 4-b). Burada amaç kaidenin ayağını olduğunca geniş tutarak tavandan gelen ağırlığın tabana yaptığı basıncı dağıtmaktır. Buna karşılık ana kaya üzerine oturtulan ya da olasılıkla ağır yük taşımayan althılarda bu uygulamaya gidilmemiş, kaide tam anlamıla silindirik biçimini korumuştur (HchI, lev. 114). Çavuştepe althı̆ı gerek dayanıksız malzemesi ve gerekse tam silindirik biçimiyle bu ikinci türe girmektedir (Res. 4-a). Yukarıda da değindiğimiz üzere, büyüklüğü ve tam durumda olması nedeniyle altlı̆ın kaleden yuvarlanmış olabileceği olassılığını çok az bulmaktayız. Buna karşılık bu yörede, yani kalenin güney eteğindeki bir yapıda kullanılmış olabileceğinin de düşünülebileceği inancı içindeyim. Eğer bu olasılık doğruysa, söz konusu kaidenin ne gibi bir işlev yüklendiğini de araşturmak gerekir.

Urartu kralı II. Sarduri'nin İÖ. VIII. yüzyılın ortalarından hemen sonra kurduğu bu kentte, Aşağı Kale'deki İrmusini Tapınağı yazıtında anlatıldığı üzere ${ }^{8}$, Guguna (Hoşap) çayından alınan bir kanalla beslenen sebze bahçeleri veya bostanlar (GAN.MEŚ.GIŚ dan görülmemekle birlikte, üzüm bağları ya da meyve bahçeleri olduğu anlaşılmaktadır. Günümüzde kalenin güney etekleri boyunca uzanan çok eski

${ }^{8}$ Henüz yayımlanmamıs olan bu yazıtın kaba bir Türkçe çevirisi için bkz. A. Erzen, "Cavuş̧epe Kazıları", VII. Türk Tarih Kongresi I (Ankara 1972) 68. 
birkaç su kanalı bulunmaktadır ve söz konusu direk altlı̆̆ı da bunlardan birine bitişik olarak ele geçirilmiştir (Res. 3). Biri her yl yapılan bakım ve onarım çalışmalarıyla birkaç yıl önceye değin kullanılan bu kanallar basit topraktandır, bu yüzden de ne denli eski oldukları açık değildir (Res. 6-7). Bununla birlikte Çavuştepe'nin bahçe tarımı yapmaya en elverişli olan bu kuytu güney kesimi, olasılıkla Urartu bahçeleri için de güzel bir alan oluşturmuştu. Nitekim bu kanallar boyunca kimi eski kullanım izlerinin varlığı topraküstü buluntularıyla anlaşılmaktadır.

Çavuştepe sebzelik ve meyveliklerinin kalenin kuzeye tümüyle kapalı, kuytu güney etekleri ve su kanalları boyunca uzandığı görüşü benimsenecek olursa, söz konusu direk altlığının böyle bir bahçeyle ilgili olabileceği akla gelir. Yukarıda da belirtildiği üzere, özellikle II. Sargon ve Assurbanipal dönemi kabartmalarından tanıdığımız bahçe pavyonları çift sıra direkli bir konstrüksiyona sahiptir (Res. 1-2). Sıcak yaz aylarında kullanılan bir kameriye görünümündeki, genişs saçaklı ve düz damlı bu yapıların küçük boyutlu tutuldukları da belirgindir ${ }^{9}$. Çavuştepe altlı̆ının böyle hafif bir bahçe yapısıyla ilişkisi hiç de olanak dışı değildir.

Buna benzer birkaç adet kaide Van Müzesi'nde bulunmaktadır. Bunlardan biri Yukan Anzaf Kalesi'nin güneybat eteklerindeki, işlenmiş taşlarla örülü bir kuyu içinde (Hulin 1960: 205, lev. XXVII/a, c), biri de Van'da bir evin bahçesinde ele geçirilmiştir (UKN no. 85; HchI no. 53b, lev. 114). İlki $0.89 \mathrm{~m}$., ikincisiyse $0.72 \mathrm{~m}$. çapındaki her iki örnek de kırık olup yükseklikleri belli değildir; mevcut yükseklikler ise $0.20 \mathrm{~m}$. kadardır (Res. 8). Dayanıksız kum taşından yapılmış olan althklardan ilkinin üst yüzünde 0.66 $\mathrm{m}$. çapında ve $0.03 \mathrm{~m}$. yüksekliğinde, daha kaba bırakılmış yuvarlak bir alan vardır ki, direğin bu çıkınt üzerine oturtulduğu açıkur (Res. 5-c). Kaidenin üst yüzeyinde ahşap direğin oturtulacağı ikinci bir yükseltiye gerek duyulmuş olması bu altlı̆̆ın açık havada kullanılmış olabileceğine işaret eder. Çünkü böylelikle ahşabın, yukarıdan akacak yağmur suları ve nemden korunması konusunda esaslı bir önlem alınmış oluyordu. Çavuştepe altlığının üst yüzeyi kırık olduğundan aynı düzenin burada da olup olmadığını söylemek olası değildir.

${ }^{9}$ Evliya Çelebi (4: 558 vd.) Van Kalesi'nin hemen güneyindeki, bugün Şamramalu denen yõreden Edremit'e değin tūm ovanın bağ-bahçe ve gülistanlık olduğunu; her bağda pınar, havuz ve şadırvanın yanında birer "şirin kōşk" bulunduğunu bildirir. 
Gerek Anzaf ve gerekse Van kökenli direk altlıklarının yan yüzlerinde Urartuca yazıtlara yer verilmiştir. Bunlardan ilki İşpuini'ye, ikincisi de oğlu Minua'ya aittir ve her iki yazıtta da kralların birer É inşa ettirttikleri yazılıdır. Capları Cavuştepe'deki kadar geniş olmamakla birlikte, dayanıksız malzemeleri ve tam silindirik yapılarına bakılarak bu kaidelerin de fazla ağır bir yük taşımamış olabilecekleri söylenebilir. Yan yüzlerindeki yazıtlarında kralların birer É yani bir ev-tanrı evi, tapınak, belki de Haldi'ye adanmış bir kutsal alan yaptırttıklarını belirtmiş olmaları, altlıkların dinsel ișlevi olan bir yapıdan gelmiş olabileceğine işaret eder. Yukarıda da belirttiğimiz üzere, Urartular kimi zaman tanrılar için bağlar kurdukları gibi, kimi zaman da kendi adlarını taşıyan bağlarda tann Haldi için kurbanlar keserek törenler düzenlemekteydiler (UKN no. 65; Taffet, Yakar 1998: 146). Bu yüzden Yakın Doğu'daki gibi (Wiseman 1983: 143 vdd.) Urartular'da da bahçelerin dinsel bir anlam taşıdıkları söylenebilir.

Şimdi nerede olduğunu saptayamadığımız, Giyimli'de bulunmuş ve sonradan Münih'e kaçırılmış tunçtan bir adak levha parçası üzerinde olasılıkla böyle bir bahçe resmedilmiştir (Res. 9). Burada süslü, yüksek ve çapı geniş bir kaideye oturtulmuş daha ince bir direk ile bunun hemen önünde boğa üzerinde duran bir tanrı betimi kısmen görülmektedir. Urartu mimarlığında bu türde taşıyıcı elemanlara çok yer verilmediği, Altıntepe tapınağındaki galeriler dışında, daha çok da dikdörtgen planlı büyük depo mekanları ve ahırlarda kullanıldıkları anlaşılmaktadır (Forbes 1983: 56 vd.). Bu yüzden, adak levhası üzerinde bir tanrının karşısında görülen bağımsız taşıyıcı ögenin böyle bir bahçe pavyonuyla ilişkili olması olasıdır. İÖ. VII. yüzyıla ya da VIII. yüzyılın sonlarına tarihlenebilecek bu parça üzerinde belki de tanrı adına kurulmuş bir bağ anlatılmak istenmiştir.

Sonuç olarak: Urartu'da sulama sistemlerine yakın şekilde kurulmuş, küçük çaplı üzüm bağları ve meyveliklerin varlığı anlaşılmaktadır. Krallar, soylular ve de tanrılar için oluşturulmuş bulunan bu bahçelerde İÖ. IX. yüzyılın sonlarından başlayarak kimi direkli yapıların bulunduğu da söylenebilir. Assur'un erken örneklerindeki gibi yalnızca pratik yarara yönelik olarak düzenlenmiş bulunan bu bahçe anlayışı Sargonidler döneminin gösteri ve keyfe yönelik bahçelerinden farklı bir geleneğin ürünüdür. Sargonidler döneminde ortaya çıkan bu küçük bahçe anlayısının Assur'a, bit hilāni ile birlikte Bat'dan geldiği ileri sürülmüşse de (Oppenheim 1965: 333), bu geleneğin kökeninde -daha önce savunulduğu gibi (Wiseman 1983:137 vdd.) Urartu'dan gelen etkilerin de göz ardı edilmemesi gerektiğine inanıyorum. 


\section{BIBBLIYOGRAFYA - BIBLIOGRAPHY}

BALKAN, K., 1960. "Patnos Yakımında Aznavurtepe'de Bulunan Urartu Tapınağı ve Kitabeleri", Anatolia V: 133-158.

BELLI, O., 1994. "Urartian Dams and Artificial Lakes Recently Discovered in Eastern Anatolia",Tel Aviv 21:77-116

-, 1995a. "2800 Yıldır Çalışan Sulama Kanalı", Tarih ve Medeniyet 13: $53-57$

-, 1995b. "Neue Funde urartäischer Bewässerungsanlagen in Ostanatolien", Beiträge zur Kulturgeschichte Vorderasiens. Fetschrift für R.M. Boehmer, Mainz: 19-48.

-, 1997ª Doğu Anadolu'da Urartu Sulama Kanalları, Arkeoloji ve Sanat Yayınları. İstanbul.

-, 1997b. "1996 Yılında Doğu Anadolu bölgesinde Urartu Baraj ve Sulama Sisteminin Araştırılması", XV. Araştırma Sonuçları Toplantusı II: 163-198.

, 1997c. "Doğu Anadolu Bölgesinde Keşfedilen Urartu Barajlarına Toplu Bir Bakış", Belleten 229: 631-680.

, -1998. Anzaf Kaleleri ve Urartu Tanrları. Arkeoloji ve Sanat Yayınları. İstanbul.

BELlí, O., DínÇOL, A., 1980. "Hazine Piri Kapısı ve Aşağı Zivistan Taş Ocakları", Anadolı Araşturmaları VIII:167-190.

BOTTA, P.E., FLANDIN, E., 1849. Les Monuments de Ninive II, Paris.

BURNEY, C.A., 1966. "A First Season of Excavations at the Urartian Citadel of Kayalıdere", Anatolian Studies XVI:55-111 -, 1972. "Urartian Irrigation Works", Anatolian Studies XXII: 179186.

ÇILINGGiroĞLU, A., SALVINI, M., 1995. "Rusahinili in front of Mount Eiduru": The Urartian Fortress of Ayanıs (7th Century B.C.)", Studi Micenei ed Egeo-Anatolici XXXV:111-124

DALLEY, S., 1994. "Niniveh, Babylon and the Hanging Gardens: Cuneiform and Classical Sources Reconciled", Iraq LVI: 45-58.

DINÇOL, A., BELLİ, O., 1982. Van Bölgesinden Yeni Urartu Yazıtları, İstanbul 
DİNÇOL,A., KAVAKLI,E.,1978. "Karahan Köyünde Bulunan Dört Yeni Urartu Yazıtı", Anadolu Araraştırmaları 6: 17-43.

ERZEN, A., 1978. Cavuştepe I, Ankara.

EVLIYYA ÇELEBI, Evliya Çelebi Seyahatnamesi 1-10. Üçdal Neşriyat, İstanbul 1984-86.

FORBES, T.B., 1983. Urartian Architecture . BAR Int.Ser. 107, Oxford.

GARBRECHT, G., 1980. "The water supply system at Tushpa (Urartu)", World Archaeology II/3: 306-312.

GRAYSON, A.K., 1972. Assyrian Royal Inscriptions I, Wiesbaden. , 1976. Assyrian Royal Inscriptions II/2, Wiesbaden.

HchI, König, F.W., Handbuch der chaldischen Inschriften I-II (Graz 195557).

HUlIN, P., 1960. "New Urartian Inscribed Stones at Anzaf", Anatolian Studies X: 205-207.

LEHMANN-HAUPT, C.F. 1926. Armenien II/1, Berlin.

LAESS $\varnothing E$, J., 1951. "The irrigation system at Ulhu, 8th Century B.C.", Journal of Cuneiform Studies 5: 21-32.

LAR: Luckenbill, D.D., Ancient Records of Assyria and Babylonia II (Chicago 1927).

MOSES KHORENATSI, 1978. History of the Armenians, London.

OPPENHEIM, A.L., 1965. "On Royal Gardens in Mesopotamia", Journal of Near Eastern Studies 24: 328-333.

ÖĞÜN, B., 1970. Van'da Urartu Sulama Tesisleri ve Şamram (Semiramis) Kanalı, Ankara.

ÖZGÜÇ, T., 1966. Altuntepe. Mimarlık Anıtlanı ve Duvar Resimleri, Ankara.

PARPOLA, S., 1987.The Correspondence of Sargon II, Part I. State Archives of Assyria I, Helsinki.

SALVINI, M., 1979 " Die urartäischen Tontafeln", W. Kleiss, Bastam I. Ausgrabungen in den urartäischen Anlagen 1972-1975, Berlin. 1992. "Il canale di Semiramide", Geographia Antiqua I: 67-80. 1998. "Ein urartäische Felsinschrift in der Region Nachicevan", Zeitschrift für Assyriologie 88: 94-99. 
STEVENSON, D.W.W., 1992. "A Proposal for the Irrigation of the Hanging Gardens of Babylon", Iraq 54: 36-56.

TAFFET, A., YAKAR, J., 1998. "Politics and Religion in Urartu", Essays on Ancient Anatolia in the Second Millennium B.C. (yay.haz. T. Mikasa) Wiesbaden:133-152.

UKN, Melikishvili,G.A., Urartskie klinoobraznye nadpisi, Moskova 1960.

WISEMAN,D.J.,1983. "Mesopotamian Gardens", Anatolian Studies 33: 137144.

ZACCAGNINI, C., 1981. "An Urartean Royal Inscription in the Report of Sargon's Eight Campaign", Assyrian Royal Inscriptions: New Horizons (yay. haz. F.M. Fales) Orientis Antiqvi Collectio XVII, Roma.

ZIMANSKY, P.E., 1985. Ecology and Empire: The Structure of the Urartian State, Chicago. 
